\title{
Increased prevalence of Solar Keratoses, Infectious diseases and rising Environmental Estrogen equating with aborted blood, contraceptive menstrual blood pollution with consequent ozone depletion.
}

\author{
Elizabeth Jeya Vardhini Samuel ${ }^{1}$, Joseph Vimal ${ }^{2}$, Susan Philip ${ }^{3}$, Jobin John ${ }^{4}$ \\ PIMS, Pondicherry; \\ Engineer Karunya University \\ Assistant Professor 1,2, Post graduate Resident ${ }^{3}$ Department of General Medicine, \\ Pondicherry Institute of Medical sciences, No.20, KanagaChettikulam, Kalapet, Pondicherry, 605014, South \\ India
}

\begin{abstract}
:
Background: Simultaneous ozone layer depletion, global warming resulting in solar keratoses, skin neoplasms, increased prevalence of infectious diseases and rising environmental estrogen documented as pollutant led to this analysis.

Aims: New age practice of contraception, abortions, its probable association with increase in infectious diseases, ozone layer depletion, rising environmental estrogen is sought after.

Methods: Retrospective analysis of the prevalence of actinic keratoses, skin tumors, cancers from 2006-2013 with the data of 79 patients was undertaken; analysis of prevalence of viral fungal, rickettsial, bacterial infections, drug resistance, and its association with contraception achievement from 1970-2013 was also undertaken.

Estrogen was measured in three samples of river water near cape Comorian and four samples of sea water from four different seas namely Indian Ocean, Arabian Sea, Bay of Bengal near cape and Bay of Bengal near Union Territory of Pondicherry.

Estimation of Fetal, adult hemoglobin in sea water was attempted by routine hemoglobin electrophoresis. Estimation of alpha feto protein and $\beta$ Human chorionic gonado tropin in river and sea water was undertaken. Results: Solar Keratoses had increased 4 fold [p $<0.0005]$, tumors of the skin had increased by 3 fold [p $<0.0025]$, skin cancers had doubled [p $<0.025]$, over the past decade, as implementation of contraception progressed; incidence of new viral infections, increased incidence of fungal infections, rickettsial diseases, drug resistant microbial infections, mosquito borne diseases were corresponding with progress in implementation of contraception since 1970s.

Estrogen was detected in river water- 3-5pg/ml and sea water - 0.3- $1 \mathrm{pg} / \mathrm{ml}$.

Fetal hemoglobin could not be detected as visible bands, by routine hemoglobin electrophoresis, capable of detecting values in grams only.

Alpha feto protein was detected in sea, river water as $<0.6 \mathrm{ng} / \mathrm{ml}, \quad \beta$ human chorionic gonado tropin was detected in sea and river water as $<0.1 \mathrm{miu} / \mathrm{ml}$ confirming further, aborted blood pollution of the sea, river.

Conclusion: Concept is global practice of contraception, abortion, since $20^{\text {th }}$ century $\sim 1970$, has resulted in innocent aborted blood, contraceptive menstrual blood environmental pollution, evidenced by rising environmental estrogen; [endogenous estrogen present in the blood, can reach environment, by spilt blood only]aborted blood with its hemoglobin, binds oxygen of the environment with high affinity, cannot be replaced by plants, depletes ozone, unlike emissions of live humans-chlorine, bromine, nitrous oxide, exhaled air with carbon dioxide, being essential for manure, photosynthesis of plants, which replace oxygen molecule by molecule; plants become fossil fuels, eco balanced cycle continues to self sustenance by life on earth; ozoneexisting oxygen envelope being depleted by aborted blood, radiations result in solar keratoses, skin neoplasms; environmental aborted blood pollution favors flourishing growth of microbes, infectious diseases and drug resistance.
\end{abstract}

Key Words: Live humans; aborted blood pollution; contraceptive menstrual blood pollution; eco balanced cycle; global hypoxia.

\section{Introduction}

The new age practice of contraception, abortions were being implemented with enthusiasm, since $\sim 1960$ s; ozone layer depletion was noted since 1970; by 1980s new viruses like Human immunodeficiency 
virus, Hepatitis A, B, C, D, E viruses were emerging; microbial virulence with drug resistance was notably increasing; 1990s rising environmental estrogen was documented; hence a correlation is sought for.

\section{Methods}

Retrospective analysis of data of prevalence of solar keratoses, skin tumors, skin cancers in 79 patients seen over every two years, from 2006-2013 and correlating with progressive implementation of family welfare schemes, contraception and abortion was undertaken.

Similarly retrospective analysis of, increased prevalence of viral infections, drug resistance, less virulent fungal infections, rickettsial diseases, mosquito borne diseases from1970 -2013, correlating with contraception implementation was undertaken.

Estrogen levels were assessed in 3 samples of river water from one river of Cape Comorian, and four samples of water obtained from 4 different seas namely Indian ocean, Bay of Bengal at cape, Arabian Sea, Bay of Bengal near union territory of Pondicherry.

Hemoglobin electrophoresis was attempted in sea water to identify presence of fetal, adult hemoglobin. Alpha feto protein estimation was done in one sample each of river and sea water; $\beta$ Human chorionic gonadotropins were estimated in one sample each of river and sea water.

\section{Results}

Solar Keratoses had increased 4 fold $[p<0.0005]$, tumors of the skin including pilomatrixoma had increased by 3 fold [ $p 0.025$ ], basal cell carcinoma, malignant neoplasms of the skin had doubled over the past decade [ $\mathrm{p}<0.025$ ], corresponding with progressive implementation of contraception, abortion [figure-1a, 1b];

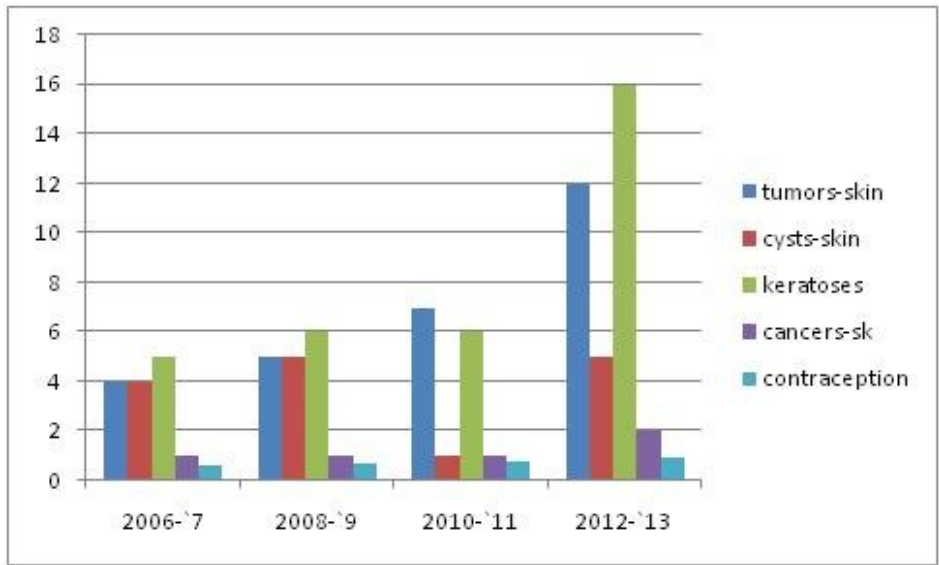

Figure1a-skin lesions and contraception

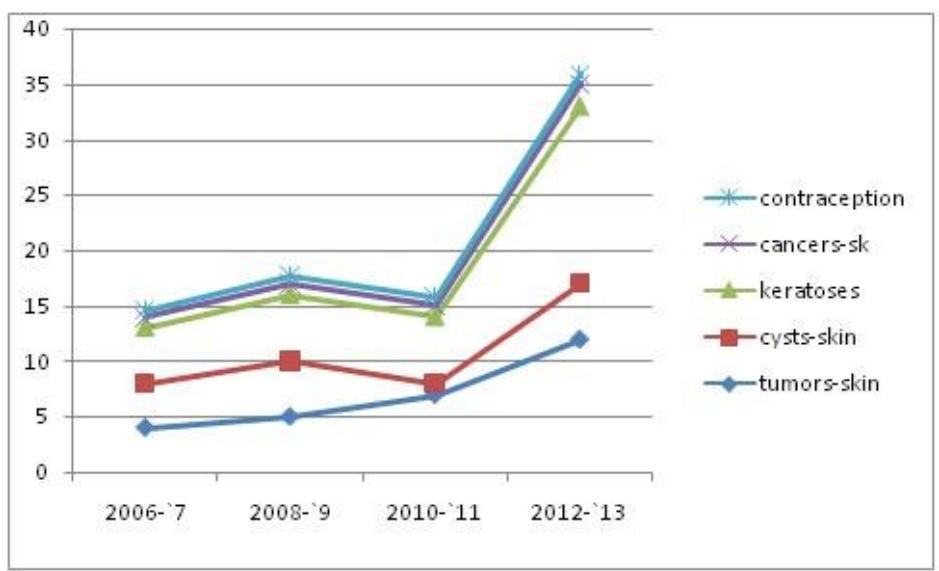

Figurelb-Skin lesions and contraception

Infectious diseases with virus, fungus, rickettsial are correspondingly [figure-2] increasing by 100 folds $[\mathrm{p}<0.0005]$ with progressive implementation of contraception as family welfare schemes. 


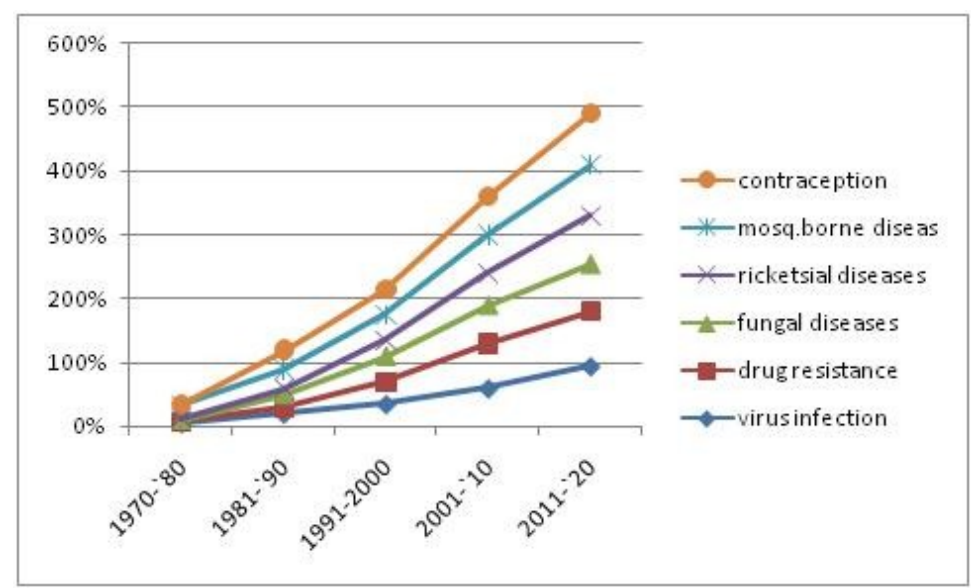

Figure2-Prevalence of infectious diseases and contraception

$3-5 \mathrm{pg} / \mathrm{ml}$ of estrogen was detected in river water, and estrogen in sea water measured $1,0.8 \mathrm{pg} 0.3 \mathrm{pg}$, $0.4 \mathrm{pg} / \mathrm{ml}$ suggesting estrogen pollution was brought by the river (3-5 fold higher), gets diluted in the sea. Attempts to detect fetal, adult hemoglobin in sea waters, by routine hemoglobin electrophoresis, failed to identify visible bands, since hemoglobin is measured in grams; if nano science can devise an instrument to measure hemoglobin by electrophoresis, in nanograms or pictograms (as we measure estrogen) in sea waters, rivers, probably we can confirm further by detecting the presence of fetal, adult hemoglobin.

Alfa feto protein was detected in river and sea water as $<0.6 \mathrm{ng} / \mathrm{ml} ; \beta$ Human chorionic gonadotropins secreted by the placenta were identified as $<0.1 \mathrm{miu} / \mathrm{ml}$ in river and sea water confirming aborted blood pollution.

\section{Discussion}

Solar Keratoses refers to, localized areas of epidermis, in which due to chronic solar exposure, epidermal growth, differentiation are abnormal and irregular; ${ }^{1}$ typically it's a raised pink or grey scaling or warty hyperkeratosis plaque or papule measuring $2.5 \mathrm{~mm}$ in diameter or may be much larger; they are found on the exposed parts of skin of elderly, fair skinned subjects who show other signs of solar damage; parakeratosis or hyperkeratosis surmount the variably thickened epidermis which demonstrates heterogeneity of cell, nuclear size, shape and staining[epidermal dysplasia]; sweat ducts are conspicuously not involved probably by the cooling effect of sweat.

Melanin is a complex brown black polymer synthesized from the amino acid dihydroxy phenyl alanine L-Dopa; melanin synthesis is catalyzed by a copper containing enzyme called as tyrosinase ${ }^{2}$ which catalyses the transformation of L Dopa to tyrosine; melanin produced in melanocytes is donated to keratinocytes via their dendrites; melanin granules ascend through epidermis in keratinocytes; mature melanosomes aggregate into melanin granules; its these granular particles, within keratinocytes give protection against ultra violet rays; melanin in keratinocytes absorbs all visible light, ultra violet rays, infrared rays; it's a powerful electron acceptor and may have uncharacterized protective functions.

Skin surface contour may also be recorded optically by reflection of light from the skin surface; sunscreens are cream or lotions that absorb and filter out or reflect off the damaging ultraviolet rays; older sunscreens had substances such as the ${ }^{3}$ esters of Para amino salicylic acid, benzoic acid, the homosalicylates, the benzophenones and the cinnamates designed primarily to filter out the sun burning $290 \mathrm{~nm}$ ultraviolet B segment; sebaceous gland secretes into the hair canal, a lipid rich substance, known as sebum, whose function is to lubricate the hair; sebum contains triglycerides, cholesterol esters, wax esters and squalene; thin film coating of lipid rich secretions of sebum can reflect visible light, absorb ultraviolet rays by their double bonds in esters; similarly olive oil, coconut oil, castor oil, or gingili oil smeared on the skin before bathing, will dissipate the heat and absorb the ultra violet rays, specially required with global warming; ultraviolet rays is readily reflected from whitish surfaces as sand, snow, white walls; significant amount diffuses through cloudy skies, so can get burnt on dull days also; nearer the equator, lesser the latitude, more direct the ultraviolet rays; due to heat the gases ascend up so the oxygen envelop, is seen in higher levels, near the poles they are condensed.

Sunlight is the most visible and obvious source of comfort in the environment; sun provides the beneficial effects of warmth and vitamin D synthesis; acute and chronic sun exposure have pathological consequences; cutaneous exposure to sunlight is a major cause of skin cancer and can have immunosuppressive effects; sun`s energy reaching the earth`s surface is limited to components of the ultraviolet, the visible and portions of infrared spectra; cut off at the short end of the ultraviolet spectrum is $\sim 290 \mathrm{~nm}$, due primarily ${ }^{4}$ to stratospheric ozone; concern about ozone destruction by a possible chlorofluorocarbons has led to the 
international agreement to reduce production of these chemicals; measurements of solar flux indicate, 20 fold regional variation in the amount of energy at $300 \mathrm{~nm}$ that reaches the earth 's surface; this variability relates to seasonal effects, the path the sunlight traverses through ozone, air, altitude[-4\%increase for each $300 \mathrm{~m}$ elevation],the latitude[increasing intensity for decreasing latitude] and the amount of cloud cover, fog and pollution; major components of the photo biologic action spectrum capable of affecting human skin include the ultraviolet and visible wavelengths between $290 \mathrm{~nm}$ and 700nm; photon energy in the visible spectrum is not capable of damaging the skin in the absence of photosensitizing chemical; photosensitivity occurs when a photon absorbing chemical (chromophore), present in the skin absorbs incident energy, becomes excited and transfers the absorbed energy to various structures or to oxygen.

Nitrogen dioxide reacts with sunlight and oxygen in a photochemical ${ }^{5}$ reaction to form ozone; ozone layer refers to a region of earth 's stratosphere, that absorbs most of the sun's ultraviolet radiation; ozone layer contains $<10$ parts per million ${ }^{6}$ of ozone; average ozone concentration in earth's atmosphere as a whole is 0.6parts per million; its mainly found in lower portion of stratosphere $20-30 \mathrm{~km}$ above earth, though the thickness varies seasonally and geographically; contains high concentrations of ozone[O3] relative to other parts of the atmosphere, although it is very small; Dobson unit is used to measure ozone ${ }^{7}$ overhead; ozone, oxygen envelope, absorbs 90-99\% of sun`s medium frequency ultraviolet rays[200nm-315nm];

Photochemical mechanisms that give rise to ozone were discovered by the British physicist-Sydney Chapman in 1930;ozone is formed ${ }^{8}$ when ultraviolet rays hit oxygen molecules containing 2 oxygen atoms, splitting them into 2 individual oxygen atoms(atomic oxygen), the atomic oxygen combines with unbroken oxygen to form O3-ozone; ozone molecule is unstable[although in the stratosphere long lived]; when ultraviolet rays hit ozone, it splits into oxygen molecule and atomic oxygen, a continuing process called the ozone-oxygen cycle; so basically its condensed oxygen, God ordained oxygen envelope, that exists to protect life on earth; short or vacuum ultraviolet rays $(10 \mathrm{~nm}-100 \mathrm{~nm})$ are screened out by nitrogen; ultraviolet radiation capable of penetrating nitrogen is divided into 3 categories, based on its wavelength; they are referred to as ultraviolet $\mathrm{A}(400-315 \mathrm{~nm})$, ultraviolet $\mathrm{B}(315-280 \mathrm{~nm})$, ultraviolet $\mathrm{C}(280-100 \mathrm{~nm})$; ultraviolet $\mathrm{C}$ rays-very harmful to living is screened by ozone and oxygen around $35 \mathrm{~km}$ altitude; ultraviolet B rays is the main cause for sunburns; can produce cataracts, immunosuppressant, genetic damage resulting in skin cancer; ozone is transparent to ultraviolet $\mathrm{A}$, constituting most of the ultraviolet rays reaching the earth, producing less harm ${ }^{9}$ to the chromosomes, although it can cause premature aging of the skin.

Ozone layer is higher in altitude in the tropics and lower in altitude outside the tropics specially in the polar regions[ probably gases rise with heat in tropics]; during winter ozone increases in depth[the snow reflects ultraviolet ray, so ozone-oxygen cycle is probably seen at lower altitude increased depth]; thickness of ozone is thinner near tropics, thicker near the poles [oxygen is split more and more, over tropics, gases expand with heat, rise up towards north pole, and condense]; thinner during autumn,[leaves would have dropped with decreased oxygen production]thicker during spring[leaves spring back restoring oxygen production]; ozone hole phenomenon, i.e. lowest ozone column is seen in Antarctica in September, October and Arctic in March, April, May[probably time of autumn, fall with no leaves, reduced production of oxygen]; ozone level of north hemisphere is dropping by $4 \%$ per decade since 1970 .

Ozone may be depleted by Nitric oxide, nitrous oxide, chlorine, bromine atoms,- all postulated ${ }^{10}$ by complex chemistry laboratory models, and their validation against observational data; oxygen envelope is existing to support life with its emissions[02-0-03-02], self sustaining ecology for, by, of life; we are trying to comprehend the facts that could lead to the ozone hole formation, which did not exist prior; the concept is most of these so called ozone depleting substances are present in the nature with a God ordained purpose for e.g. nitrogen shuts off $0-100 \mathrm{~nm}$ ultraviolet rays, nitrogen dioxide helps in ozone formation, chlorine, bromine, fluoro carbons, nitrous all are reacted, oxidized, with thunder storms, showers of rain, to become manure for plants, plants supply oxygen in exchange for the emissions, exhaled air of live humans, living; ozone is not formed over tropics, rather oxygen envelope, undergoes splitting by higher intensity ultraviolet rays of tropics, than polar regions, gases ascend up towards north pole, [top of the atmosphere the intensity is 350 times more than the earth `s surface for ultraviolet rays]have less splitting over poles, gases condense with less heat so ozone, oxygen is thicker over polar regions and thinner over tropics.

In 1985- 75\%reduction in ozone was noticed in Antarctica; chlorofluorocarbons are handled by stratosphere; iodine reacts in lower atmosphere; chlorofluorocarbons are not present in Antarctica [with little emissions], where ozone hole is enlarging[so live people's emissions are not the cause for oxygen envelope depletion] to include southern parts of Australia(where 50\% of people above 40 years develop solar keratoses), Newzealand, Africa, Chile, Argentina; hence chlorofluorocarbons are tell tales of human existence and inventions using earth's resources, beautifully dealt with, by existing stratosphere-self sustained ecology for and by life; we had more emissions before 1970s but the ozone, oxygen was stable, because live humans with their emissions serving as food, manure, care taker, for plants, could get oxygen replenished molecule by molecule by plants. 
Whereas $\sim 1960$ s new age practice of contraception, abortion, progressively, enthusiastically got implemented, annihilating live humans, with innocent aborted blood, contraceptive menstrual blood pollutant, binding oxygen with high affinity, cannot be replaced by plants, plants also perish with hypoxia, obnoxious innocent aborted blood pollution, flourishing microbes, since live humans with emissions have gone down the drain; live humans, their emissions, as God ordained growth of population, without curbing child birth, is mandatory for oxygen replenishment by plants, stable self sustaining ecology, oxygen envelope, ozone, to prevent ozone layer depletion

Any amount of forestation cannot replace the oxygen depleted by innocent aborted blood because live people with their emissions are absent; hence the oxygen depletion is progressive, cumulative leading to global hypoxia as a result of global contraception, abortion.

In 1994 Dr.Susan Jobling of Brunel University ${ }^{11}$ of United Kingdom, observed that estrogenic compounds are the pollutant in river waters, when they attempted to find the pollutant responsible for the disappearance of fish.

In 1998 Professor Paul Devroey, identified 'estrogen like particles are in the rise in the ${ }^{12}$ air' as pollutant, when they attempted to analyze the cause for increase in infertility.

Global abortion summary mentioned 863,000,000 reported ${ }^{13}$ surgical abortions till 2010; 498 abortions per minute in the globe; United nations mentioned 3,750,000 reported surgical abortions /year; estrogen is a steroid hormone derived from ${ }^{14}$ cholesterol[hence it gets the name-cholesterol-steroid], secreted directly into the blood, circulates in the blood, bathes, nurtures each cell; its surveillance is essential for cell differentiation, controlled multiplication, cell ${ }^{15}$ metabolism, cell cycle, essential for genomic repertoire;.

Unless blood is shed estrogen cannot reach the environment; during teen age estrogen levels will be 100pg-300pg [trillionth-a very small amount]; $>37$ years-the estrogen levels decrease to $15 \mathrm{pg} ; \sim 80$ years, estrogen levels will be $5 \mathrm{pg}$; during pregnancy placenta has to secrete $4200 \mathrm{pg}$ of estrogen, otherwise the fetus will be spontaneously aborted around $3^{\text {rd }}$ month, called as placental switch over insufficiency.

If a person $>50$ years' blood is spilt by murder, $150 \mathrm{ml}$ of blood loss $\times 15 \mathrm{pg}=2250 \mathrm{pg}$ estrogen contaminant to the environment; if a teenager's blood is spilt by accident then $150 \mathrm{ml}$ of blood loss $\times 300 \mathrm{pg}=45000$ pg estrogen contaminant to the environment;

when a pregnancy is aborted eg.498 abortions /minute $\times 60$ minutes $\times 24$ hours $\times 365$ days $\times 60$ 80 years $\times 4200 \mathrm{pg}$ of estrogen $\times 350 \mathrm{ml}$.blood loss $=$ estrogen pollutant of the air, water;

if a mother is blessed with 10 children she will not menstruate for minimum 200 months or 20 years, of the $\sim 25$ years menstrual span; whereas with contraception, small family norms, a lady menstruates 200 months more; so $1989,375,754$ women of reproductive age group $[15-45$ years $] \times 350 \mathrm{ml}$ blood loss/menstruation $\times 300$ pgm estrogen $\times 200$ months/woman=environmental estrogen pollutant;

Global innocent aborted blood, contraceptive menstrual blood polluted air, water inhalation, ingestion respectively; rising environmental estrogen equates with innocent aborted blood, contraceptive menstrual blood pollution of air, water.

Innocent aborted blood, contraceptive menstrual blood with its hemoglobin, binds avidly to oxygen of the environment, and cannot be replaced by plants, unlike emissions; since live humans, with their emissions are made extinct, which is food, manure for plants, disabling replenishment of oxygen, resulting in ozone layeratmospheric, environmental oxygen depletion, global hypoxia, global warming, disappearance of fish, islands, birds, grapes, solar keratoses, soaring infectious diseases; hot air currents resulting in inevitable tsunamis, tornadoes, hurricanes, cyclones, floods, earthquakes.

Innocent aborted blood, contraceptive menstrual blood pollutant of the waters, indicated by estrogen pollutant of waters by Dr. Susan Jobling, accounts for depletion of water's oxygen by the hemoglobin of innocent aborted blood, leading to hypoxia of waters and disappearance of fish; lakhs of fish came ashore dead due to ' unknown hypoxia 'along Los Angeles in March-2011; its predicted 98\%of sea food will disappear by 2048; most of the islands will disappear by 2050, by same innocent blood depleting oxygen of the environment, global warming, sea level rising, earthquake coupled with tsunamis; we need oxygen to breathe?!; let the babes, lives on earth continue luxuriously, then oxygen envelope will remain sustained.

New viruses had emerged since 1980s namely Hepatitis A, B, C, D, E, Human immunodeficiency virus, SARS virus, H1N1 virus, encephalitis viruses; Chikungunya virus, dengue viral illnesses though were existing already, it was known by curriculum, but in the past decade we have treated thousands of people with chikun gunya, dengue fever-strains isolated were that from our neighbor country, wherein compulsory abortions up to 25 times per lady, is practiced to implement one child policy, with their high innocent aborted blood pollution, promoting the virus transit from its native soil to our country where permanent sterilization is implemented..

$\sim 2003$, Escherichia coli bacteremia resisted meropenem, requiring Tazobactum combination, whereas in 1980s ampicillin was sufficient to curtail Escherichia coli bacteremia to bring alive patients from coma, with liver disease; less virulent fungal infections are isolated more frequently in blood cultures, e.g. Candida; 
increased incidence of rare fungal infections are seen in skin swellings as abscesses in 2013; scrub typhus presents with multiorgan dysfunction since 2010; saprophyte barkholderia pseudomallei -melioidosis, produces morbidity, mortality, with multi focal abscesses by2013; mosquito borne diseases namely chikungunya, dengue, Filariasis, malaria are on the rampant increase because aborted blood, contraceptive menstrual blood pollution is food for mosquitoes promoting vector borne diseases.

If some equipment can detect fetal, adult hemoglobin in river, seas, air, by electrophoresis capable of measuring in nanograms or pictograms, as we have detected estrogen, it'll further confirm this manuscripts' statements; since routine hemoglobin electrophoresis measuring in grams could not detect any visible bands in sea water.

Alpha feto protein detected in sea, river water and $\beta$ human chorionic gonadotropins [secreted by the placenta]detected in river, sea water representing fetal, trophoblastic components further confirm aborted blood as documented pollutant resulting in global hypoxia, warming, ozone layer depletion, tsunami's, earthquakes, tornadoes, disappearance of islands, fish, grapes, cyclones, flash floods, rise in infectious diseases.

We invest on people; live humans have disappeared, hence the global recession.

\section{Conclusion}

The concept is, enthusiastic, unprohibited, new age practice of global contraception, abortion since 1960 s, has resulted in innocent aborted blood, contraceptive menstrual blood as environmental pollutant, documented, evidenced by rise in environmental estrogen, demonstration of alpha feto protein, $\beta$ human chorionic gonadotropins in river, sea water; aborted blood pollution with its hemoglobin and its high affinity to bind oxygen of the environment has led to, progressive, cumulative oxygen depletion of the air, water, ozone depletion; increase in solar radiation, solar keratoses, skin neoplasms; aborted, menstrual blood is a rich media for microbial growth, virulence, drug resistance, less virulent infections namely fungal, rickettsial diseases to become increasingly prevalent and incidence of new viruses like human deficiency virus, Hepatitis A ,B C,D,E viruses, SARS, H1N1; mosquito borne diseases are on the increase, because human blood which is food for mosquito is freely available in the environment by abortions, contraception

Live humans with their emissions, which are food, manure, for plants, enable definite replenishment of atmospheric, environmental oxygen molecule by molecule, in exchange for carbon dioxide; chlorine, bromine, nitrous, fluorocarbons containing emissions reacted by stratosphere, with thunderstorms become manure for plants.

Growing human resources, with their emissions, are mandatory for stable, self sustaining, God ordained, existing ecobalanced cycle of oxygen envelope, ozone and economy; existing atmospheric oxygen split by ultraviolet rays to form atomic oxygen, ozone, oxygen molecule[02-0-03-02]; again ozone also splits under radiation to form oxygen molecule; hence its thinner over tropics, whereas intensity of radiation is less towards polar region, gases ascend up towards the north pole; the ozone envelop is thicker and deeper since the white snow reflects the ultraviolet rays from the surface; its thinner during autumn, fall due to absence of leaves to produce oxygen; with spring, plants sprout back, oxygen, ozone envelop grows thicker; as the oxygen is depleted by contraception, abortion in inhabited areas over tropics and temperate climates, condensed gases of the poles,[ which are denser in poles due to decreased heat, gases rise towards north pole;] move away from polar regions towards oxygen depleted areas, producing holes in the ozone in Antarctica; regions towards Antarctica are vigorously practicing contraception, abortion, than the countries of north pole , e.g.-Sweden, Ireland; as oxygen over inhabited tropics, temperate zones is depleted by contraception and abortions, gases will move from poles, towards the tropics, temperate zones; more depletion in the Antarctica, than north pole because, due to ascension of gases towards north pole[heights] condensation, density is more in the Arctic zone, predicting a slower depletion in the Arctic's than Antarctica;

Sulphur dioxide, nitrous oxide are managed in the stratosphere, they are manures for the plants; most of these so called ozone depleting substances are present, exist in nature; hydrofluoric carbons are not synthesized in polar region to produce holes in ozone and God ordained mechanisms of dealing with man's emissions exist in stratosphere, e.g. iodine reacts in lower atmosphere; it's the innocent aborted blood, contraceptive menstrual blood pollutant, dwindling humans, with less emissions, result in depletion of existing environmental oxygen, ozone -O3, producing hypoxia of waters, air, hole in oxygen envelope, ozone.

Urgent treaties, international policies are required to halt abortions, contraception, with reversal of temporary, permanent contraception, by bringing awareness, change in curriculum; implementation of contraception reversal as tubal recanalisation using the same family welfare infrastructure to do the reverse with extra surgical expertise; global recession, warming, hypoxia, annihilation, terrorism will recede.

\section{Key Points:}

- Rising environmental estrogen was documented in 1994, 1998 in water, air respectively.

- Rising environmental estrogen equates with innocent aborted blood, contraceptive menstrual blood as environmental pollutant 
- Aborted blood binds with environmental oxygen and cannot be replaced by plants resulting in progressive, cumulative depletion of oxygen; as against live humans and their emissions, which is food, manure for plants.

- Uncurbed growth of human resources with their emissions, are mandatory for stable environmental oxygen, ozone

- Humans with their emissions, replenish oxygen, by leaves` photosynthesis, maintain existing ozone, eco balanced cycle

- Humans made extinct without their emissions, instead aborted blood pollutant, leads to solar keratoses, rise in infectious diseases.

- Postulated ozone depleting substances are mostly present in nature, with a purpose e.g. becomes manure for plants by thunderstorms-selfsustaining ecobalanced cycle for, by live humans, living

- Fluorocarbons, bromine, chlorine, iodine -tell tales of man`s inventions, existence using earth `s natural resources, react in environment at many levels, but have not depleted oxygen, ozone over centuries.

- Antarctica has meager fluorocarbons, where ozone hole is prominent, since oxygen from Antarctica ascends up to tropics, temperate zones, to replace lost oxygen by contraception, abortions practiced in tropics.

- Save precious lives, babes, fetuses, germ cells, humans, people, from prevention, termination; let them grow uncurbed, we'll save ozone, oxygen-God ordained calculation, existing in nature.

- Oil smeared on the skin, cholesterol, essential fatty acids consumed, secreted in sebum, reflects, absorbs ultraviolet rays ,to reduce solar keratoses

- Urgent policies to halt global abortions, to implement contraception reversal are essentially urgent.

\section{Conflicts of Interests: None Declared}

\section{References:}

[1]. R.Marks: Keratoses; Roxburgh`s Common Skin diseases; $17^{\text {th }}$ edition; 2003; page-207

[2]. R.Marks: Melanin ; Roxburgh`s Common skin diseases; 17thedition; 2003;-page-296

[3]. R.Marks: Sunscreens, sebum; Roxburgh`s Common skin diseases; $17^{\text {th }}$ edition; 2003;-pages-9,15,30

[4]. Alexander G Marners, David R Bickers: Photosensitivity; Harrison`s Principles of Internal Medicine; $18^{\text {th }}$ edition, 2012, volume-1, pages 440-441

[5]. C Haslett, ER Chilvers, Corris: Ozone; `s Principles and practice of Medicine; $19^{\text {th }}$ edition, 2002, page-514

[6]. All Science: Basics-Retrieved 2007-01-29

[7]. Ozone Layer: Retrieved 2007-09-23

[8]. NASA Facts Archive; Retrieved 2011-06-09

[9]. Deevya L Narayanan MPH, CPHI, Rao N. Saladi MD, Joshua L. Fox MD,FAAD2: Review; UV radiation and skin cancer; International journal of dermatology, volume49, Issue9 p978-986, sept.2010

[10]. Energy Information: administration/emissions of green house halocarbons; retrieved1996(2008-06-24)

[11]. Susan Jobling-Brunel University, United Kingdom: Endocrine disrupting Estrogenic compounds in water

[12]. Professor Paul Devroey; Air-Estrogen, Ground, Odyssey volume 4, Issue 1998;pp4

[13]. Sourcehttp://www.johnstonsarchive.net/policy/abortion/wrip3310.html global abortion summary

[14]. Bruce R Carn Jean D Wilson; Disorders of the ovary and female reproductive tract; cholesterol essential; Harrison`s Principles of Internal Medicine; $11^{\text {th }}$ edition, 2pages-1820-1821

[15]. John Mendesohn: Principles of Neoplasia; Principles of Internal Medicine-1 $1^{\text {th }}$ edition; volume-1 page-422-423 